\title{
Laboreal
}

Volume $4 \mathrm{~N}^{\circ} 1$ | 2008

Ergologia, trabalho, desenvolvimentos

\section{Atividade humana e gestão da saúde no trabalho : elementos para a reflexão a partir da abordagem ergológica}

Activité humaine et gestion de la santé au travail : éléments pour une réflexion à partir de l'approche ergologique

Activité humaine et gestion de la santé au travail : éléments pour une réflexion à partir de l'approche ergologique

Human activity and health management at work: Elements for reflection based on the ergologic approach

\section{Eliza Echternacht}

\section{OpenEdition}

Journals

\section{Edição electrónica}

URL: http://journals.openedition.org/laboreal/11772

DOI: $10.4000 /$ laboreal. 11772

ISSN: 1646-5237

\section{Editora}

Universidade do Porto

\section{Refêrencia eletrónica}

Eliza Echternacht, « Atividade humana e gestão da saúde no trabalho : elementos para a reflexão a partir da abordagem ergológica », Laboreal [Online], Volume $4 N^{0} 1 \mid 2008$, posto online no dia 01 julho 2008, consultado o 20 outubro 2019. URL : http://journals.openedition.org/laboreal/11772 ; DOI : 10.4000/laboreal. 11772

Este documento foi criado de forma automática no dia 20 outubro 2019.

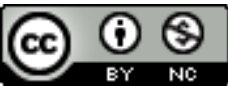

Laboreal está licenciado com uma Licença Creative Commons - Atribuição-NãoComercial 4.0 Internacional. 


\section{Atividade humana e gestão da saúde no trabalho : elementos para a reflexão a partir da abordagem ergológica}

Activité humaine et gestion de la santé au travail : éléments pour une réflexion à partir de l'approche ergologique

Activité humaine et gestion de la santé au travail : éléments pour une réflexion à partir de l'approche ergologique

Human activity and health management at work: Elements for reflection based on the ergologic approach

\section{Eliza Echternacht}

\section{NOTA DO EDITOR}

Manuscrito recebido em : Março/2008

Aceite após peritagem em : Junho/2008

1 As transformações dos sistemas de produção ocorridas entre a primeira revolução industrial e as atuais formas do capitalismo globalizado acompanham-se de mudanças importantes nos modos de viver, trabalhar e adoecer dos diversos povos. Tais transformações afetam todos os níveis e esferas da produção, das relações de competitividade empresariais às bases técnicas e organizacionais produtivas, atingindo a divisão internacional do trabalho, o conteúdo do trabalho e as condições de gestão da saúde no trabalho.

2 A crescente complexidade dos processos de adoecimento das populações trabalhadoras se expressa, desde o último século, como problema epidemiológico. o Simpósio Internacional sobre as Novas Epidemias em Saúde Ocupacional (Helsinquia, Finlândia, 
1994) e o Décimo Simpósio Internacional de Epidemiologia na Medicina do Trabalho (Como, Itália,1994) versaram sobre uma longa lista de potenciais novas epidemias ocupacionais, envolvendo as síndromes músculoesqueléticas, as síndromes psíquicas, as síndromes de hipersensibilidade (Sensibilidade química múltipla, Sick-building, novos distúrbios asmáticos, novos resultados de alveolite), as mortes súbitas (Karoshi, morte aguda dos trabalhadores tailandeses, morte súbita dos mineradores russos), entre outras.

\footnotetext{
"As epidemias modernas não são mais exclusivamente somáticas; as respostas psicossomáticas ou psicológicas, ou uma combinação dos três tipos, pode ser constatada como resultados. (...) Vários tipos de fatores físicos, químicos, fisiológicos, psicológicos e suas numerosas combinações estão associados com a ocorrência de novas respostas psicossomáticas, músculoesqueléticas, tóxicas, imunológicas ou de hipersensibilidade e podem produzir resultados difíceis de se identificar pelos métodos clássicos da medicina clínica." (Rantanem, 1995, p. 140)
}

3 As atuais práticas preventivas não têm alcançado a gênese patológica das atuais situações de vida e trabalho, o que se revela na prevalência e incidência de patologias de várias ordens entre variados países e setores produtivos. As patologias músculoesqueléticas bem exemplificam este fenômeno :

\footnotetext{
“Apesar do considerável desenvolvimento das pesquisas sobre os distúrbios músculoesqueléticos, a progressão da patologia continua. Na França, revelase um crescimento exponencial de novos casos. O que nos interroga sobre a relação entre os conhecimentos necessários à compreensão da amplitude da patologia e de sua etiologia, e os conhecimentos necessários às medidas preventivas".(Coutarel, Daniellou \& Dugué 2005, p. 3)
}

Por serem fenômenos recentes e complexos, tais impactos da transformação das condições concretas do viver e do trabalhar sobre a saúde das populações trabalhadoras ainda são pouco compreendidos. Porém, algumas tendências se delineiam, configurando novas demandas em torno do conhecimento e dos saberes necessários à instrumentação das ações preventivas sobre os modos de adoecer no trabalho e das dificuldades analíticas que aí se originam, o que inclui a própria delimitação do objeto Saúde Prevenção Trabalho.

5 Entre as inúmeras questões que aí emergem, nos concentraremos aqui em uma delas : como ampliar os campos de possibilidades de ação preventiva sobre os impactos dos novos modos de viver e trabalhar na saúde das populações trabalhadoras?

\section{Alguns pressupostos}

\subsection{As interfaces Produção/Saúde}

6 Na busca de elementos de resposta para essa questão, nosso posicionamento disciplinar situa-se em zonas de interface que se configuram entre os campos do conhecimento nomeados Produção e Saúde, aqui representados pelas grandes áreas da Engenharia de Produção e da Saúde Coletiva. 
7 O campo da Saúde encontra-se, de modo irredutível, vinculado às múltiplas instâncias da realidade social em termos empíricos e conceituais. Logo, a problemática teórica e metodológica que a ele se refere possui necessariamente abrangência pluridisciplinar : o campo da Saúde se refere a uma realidade complexa que demanda conhecimentos distintos integrados e que coloca de forma imediata o problema da intervenção. Neste sentido, ele requer como essencial uma abordagem dialética que compreende para transformar e cuja teoria, desafiada pela prática, a repense permanentemente. (Minayo, 1993, p. 15)

9 A complexidade aí contida traz para este campo teórico um conjunto de desafios, expressos por Minayo (1993) como “...dificuldades de aproximação do objeto, de vencer dicotomias analíticas, de se mover no terreno da totalidade das dimensões que o fenômeno saúde/doença revela e oculta." (idem, p. 17).

Ao nos dirigirmos à investigação dos conteúdos das mediações vinculadas aos fenômenos saúde e doença como fundamentos para uma concepção preventiva, compartilhamos com Minayo a seguinte premissa :

“...trata-se de incorporar, conceitualmente, a evidência empírica de que a saúde e a doença não se reduzem a uma experiência orgânica, biológica e objetiva, mas que a doença é também uma realidade construída e o doente é um personagem social". (Minayo, 1993, p. 21)

11 As interfaces entre a saúde coletiva e as engenharias constroem-se na medida em que essas mobilizam saberes que “... concretizam a ciência e a tecnologia, resolvendo problemas que a necessidade do viver fazem surgir em cena, necessidades conjunturais e historicamente determinadas." (Vidal,1993, p. 4). A Engenharia de Produção, em sua especialidade de organizar sistemas de produção eficientes, compartilha com a saúde coletiva demandas sociais que nos exigem respostas para múltiplas indagações, entre as quais destaco as seguintes : quais são os critérios de eficiência produtiva norteadores do atual processo de estruturação produtiva global ? Como tais critérios se concretizam em estruturas socio-técnicas singulares? Quais os seus significados quanto à lógica valorativa que os prescrevem ? Como avaliar esses critérios quanto à sua adequação à realidade do trabalho em suas múltiplas configurações?

12 Frente à estas indagações, duas outras premissas nos norteiam (Echternacht,1998). A primeira afirma que os critérios de eficiência aplicados às diversas configurações sóciotécnicas, devem refletir ambos os conteúdos da lógica valorativa dos processos produtivos, quais sejam, os conteúdos de desempenho (produtividade e qualidade dos processos e produtos) e os conteúdos dos modos de viver e trabalhar em suas relações com a dinâmica dos sistemas de produção. O que significa que a concepção e a implantação de critérios de eficiência no atual contexto de estruturação produtiva deve refletir as particularidades dos processos de adaptação das diversas coletividades trabalhadoras em seus limites e possibilidades de construção e de gestão da saúde no trabalho. Vidal (1993) define este duplo conteúdo como um princípio da seguridade tecnológica :

"uma postura básica e ética para a Engenharia, orientada em termos da análise crítica das situações e das tendências tecnológicas, visando a permanente melhoria da tecnologia atual e futura, quanto à sua adequação às pessoas, aos contextos e às populações. Adequação às pessoas que concretizam a produção, o que abrange tanto o ambiente físico, o mobiliário, 
os programas, os softwares, a organização, os sistemas de motivação. Adequação aos contextos de modernização, de reestruturação, de crescimento e retração, de rearranjos e transferência de instalações, de transferência de tecnologia. Adequação à população de trabalhadores com seus itinerários de formação, vivência e experiências profissionais, em seus regimes específicos de trabalho. (Vidal, 1993, p. 5)

13 A segunda premissa afirma que a articulação destes conteúdos em uma prática integrada impõe tratar a questão da eficiência produtiva do ponto de vista da realidade do trabalho, o que significa "considerar a atividade de trabalho como elemento crucial do uso e manuseio de tecnologias" (Vidal, 1993, p. 12). Trata-se de um duplo desafio de complexidade que nos direciona, por um lado, a uma importante interdisciplinaridade na Engenharia, e por outro, às contingências que dizem respeito às ações humanas no mundo do trabalho e aos trabalhadores e suas necessidades. Considerar esta dupla dimensão do problema, no enfrentamento de tais desafios, é uma condição para que a Engenharia de Produção consiga ser eficiente em sua função básica de estruturar a atividade de seres humanos no interior de sistemas de trabalho.

\subsection{A construção dos saberes sobre o trabalho}

14 Nossas referências aqui compartilham caminhos construídos por Oddone a partir dos trabalhos desenvolvidos na empresa Fiat de Turin, e Wisner, enquanto co-fundador de uma ergonomia da atividade.

15 Os processos de construção de competências necessárias à compreensão das relaçães saúde-trabalho, envolvem a confrontação entre os saberes formais e os saberes oriundos da experiência. Para Oddone (1981) a experiência operária se constitue como o cerne de toda análise sobre o trabalho, reconhecendo-a como aprendizagem que se constitue a partir da apropriação singular de modelos genéricos que evoluem através da prática: "A experiência operária é um processo contínuo de reapropriação de modelos"(idem, p. 202, tradução livre). A abordagem de Oddone, ao buscar integrar o ponto de vista dos trabalhadores na análise das questões de saúde, segurança e higiene do trabalho, interroga o estatuto dos saberes formais e instaura um valor científico aos saberes da experiência operária: “...esta experiência representa uma massa de conhecimentos de valor científico apreendidos na prática de vários anos de trabalho $\mathrm{e}$ que é um patrimônio dos trabalhadores" (idem, p. 189, tradução livre). A noção de "comunidade científica ampliada" (idem, p.217, tradução livre) centra-se sobre a necessária interação dialética entre os modelos práticos, oriundos da experiência operária e os modelos teóricos, instituídos e formalizados pelas disciplinas acadêmicas, como condição para a transformação das relações entre saúde e trabalho.

Os trabalhos de Ombredane e Faverge publicados em L'analyse du travail, em 1955, são reconhecidos por Wisner (1995) como origem da Análise Ergonômica do Trabalho desenvolvida pela escola francesa de ergonomia. Essa origem relaciona-se a uma ruptura com a tradição científica clássica cujos modelos teóricos determinam a apreensão da realidade, elegendo-se, a partir daí, o terreno onde situa-se o trabalho real como fonte dos problemas concretos a serem compreendidos e resolvidos pela ciência. Ao afirmar que "a prática ergonômica depende irredutivelmente das situações às quais ela se dirige" (idem, p. 117, tradução livre), Wisner nos aponta a diversidade das situações de trabalho como orientadora do olhar sobre o trabalho real. Aqui, a 
noção de variabilidade humana, técnica e social, fornece as bases para uma teorização em torno das polaridades trabalho prescrito e trabalho real, onde a atividade humana de trabalho configura singularmente cada situação de trabalho. Reconhecer a inteligência dos trabalhadores e acessar a complexidade do trabalho real torna-se condição para o desenvolvimento de modelos científicos. Aqui a intervenção sobre as situações de trabalho transforma-se, de uma aplicação de saberes, em uma reconfiguração dos conhecimentos necessários à transformação, cujas referências fundamentais encontram-se no terreno da atividade humana de trabalho.

Os caminhos construídos por Oddone e Wisner constituem patrimônios da Abordagem Ergológica (Schwartz, 2000), na qual nos referenciamos aqui na busca de luzes para a reflexão. $O$ elo entre estas referências centra-se sobre o ponto de vista da atividade humana como posicionamento epistemológico, o que significa re-incorporar os sujeitos do trabalho aos esforços necessários para a re-configuração das práticas no tocante às relações saúde-prevenção-trabalho.

\section{O objeto Saúde-Prevenção-Trabalho}

Constatamos, no último século, mudanças importantes nos padrões de morbidade/ mortalidade da população mundial. Nos países centrais, as patologias degenerativas, cardio-vasculares, osteo-musculares, mentais, entre outras - tendem a substituir o padrão anterior, caracterizado pelas doenças infecciosas e parasitárias. Nos países periféricos, incluindo-se o Brasil, não observaremos esta transposição de padrões epidemiológicos. Ao contrário, nos deparamos com uma concomitância de modos antigos e modernos de adoecer e morrer, na medida em que uma população já submetida a condições precárias de vida, em suas especificidades de reprodução enquanto indivíduos e grupos sociais, se insere, como força de trabalho, na transformação dos processos de produção. No âmbito das relações mais diretas entre saúde e trabalho, essa concomitância se traduz na coexistência de elementos oriundos de modos antigos e modernos de produzir e trabalhar. Às patologias ocupacionais clássicas, tais como pneumoconioses, intoxicações químicas, surdez ocupacional, relacionadas às condições insalubres de trabalho, associam-se modos ditos modernos de adoecer no trabalho, tais como os distúrbios musculoesqueléticos e os distúrbios psíquicos, relacionadas ao conteúdo penoso do trabalho. Por outro lado, podemos verificar uma pulverização de determinados elementos de risco por entre diversos setores produtivos e situações de trabalho. A disseminação dos distúrbios musculoesqueléticos, desde os anos 90 , por entre inúmeros setores da vida produtiva da indústria ao setor de serviços, ilustra esse aspecto.

Em suma, produzimos sinergias de situações de risco à integridade psicobiológica humana e sinergias de quadros clínicos a elas associadas. E aqui se situa um dos grandes problemas relacionados ao diagnóstico dos processos de adoecimento em suas relações com o trabalho. Trata-se das dificuldades de leitura e delineamento das diversidades de quadros clínicos em suas relações com as sinergias das situações de risco. A superação dessas dificuldades encontra como um dos obstáculos a noção especializada e fragmentada do corpo em atividade de trabalho que embasa as práticas diagnósticas e preventivas.

20 A dicotomia analítica entre processos de adoecimento físicos e psíquicos no trabalho ilustra esse aspecto. Por exemplo, sabemos que são altos os índices de afastamento no 
trabalho em centrais de tele-atendimento no Brasil por dois principais motivos: o sofrimento psíquico em suas diversas manifestações e o sofrimento músculoesquelético, codificado como LER/DORT. Esses são grupos diagnósticos especializados e distintos que aparecem como entidades isoladas no cenário da prevenção e pouco auxiliam o alcance da eficiência das práticas preventivas.

Uma outra face dessa mesma questão diz respeito às dificuldades de hierarquização dos diversos fatores de risco reconhecidos como inferentes nos processos de adoecimento das coletividades trabalhadoras. $O$ que nos remete à também difícil modelagem dos elementos estruturais das situações de trabalho patogênicas. Mais uma vez a problemática relativa aos distúrbios musculoesqueléticos pode nos exemplificar tal questão. Sabemos que tais lesões são causadas por múltiplos fatores, relacionados às interfaces organizacionais, técnicas e humanas presentes nas situações de trabalho. Mas, como se relacionam hierarquicamente as características da divisão do trabalho e da base técnica a ela associada, as exigências de produtividade e a altura de um posto de trabalho como fatores de risco? Os modelos multi-fatoriais que tentam explicar a causalidade da doença pouco nos auxilia no sentido da hierarquização desses fatores frente às demandas de prevenção. Resulta daí que as práticas preventivas tendem a enfatizar níveis localizados de intervenção, tais como as adequações dos postos de trabalho, com resultados insuficientes do ponto de vista preventivo. Tal questão terá também fortes impactos sobre os processos de estabelecimento de nexos de causalidade, fundamentais para o reconhecimento formal das patologias do trabalho frente à seguridade social.

Atuar preventivamente sobre as relações saúde trabalho pressupõe prévias concepções do que seja a saúde e o trabalho. Enquanto elaborações teóricas e instrumentais, as doenças no trabalho são derivadas de modelagens das relações entre os homens e o trabalho, entre as quais configura-se a gestão da saúde no trabalho.

Os atuais modelos hegemônicos, baseados nas heranças da História Natural da Doença, pressupõe a multicausalidade através do estabelecimento de uma rede de relações causais entre os fatores de risco tidos como inferentes, e as doenças, reconhecidas como conjuntos de sintomas e disfunções fisiológicas.

Por outro lado, o ato de trabalhar é concebido como execução de tarefas em um meio que contém determinados fatores de riscos, pressupondo uma relação de heterodeterminação do meio sobre o corpo humano (Echternacht, 1998).

Thébaud-Mony (2006) ao questionar os modelos de referência na elaboração dos conhecimentos voltados para as relações entre trabalho e câncer enfatiza os limites dos modelos biomatemáticos enquanto instrumentos especialmente reconhecidos como científicos na produção de conhecimentos no campo da saúde pública : 


\begin{abstract}
"O conhecimento e a compreensão das desigualdades sociais face ao câncer e do papel do trabalho frente a estas desigualdades se restringem aos limites da abordagem epidemiológica clássica. Mesmo se os modelos utilizados pela epidemiologia levam em conta e hierarquizam uma série de fatores de causalidade, o câncer é considerado em referência ao modelo biológico unívoco de uma relação entre uma patologia e as características individuais de exposição à certos riscos. 0 trabalho é também reduzido a esta exposição profissional individual a um ou mais cancerógenos, sem levar em conta o que torna um câncer um processo complexo onde se articulam histórias individuais e coletivas, influenciadas por lógicas políticas, econômicas, sociais e culturais."(Thébaud-Mony,2006, p. 5, tradução livre)
\end{abstract}

As questões aqui levantadas referem-se à suficiência ou à pertinência destes modelos para a compreensão dos modo de adoecer no trabalho e às possibilidades de intervenção que aí se configuram :

\begin{abstract}
"O modelo da relação saúde-trabalho ao qual se referem concretamente as práticas preventivas tem por fundamento conhecimentos fragmentários tanto no domínio da saúde quanto no domínio do trabalho. As concepções de saúde e trabalho aos quais esse modelo se refere não permitem pensar suas relações. Ele não se baseia nem sobre a saúde, nem sobre o trabalho, mas sobre a degradação da saúde de uma parte e sobre os fatores de riscos no trabalho, de outra parte"(Duraffourg, 2008, p. 160, tradução livre).
\end{abstract}

Afirmamos aqui, junto a Duraffourg (2008), que os limites destes modelos se referem à ausência de uma elaboração conceitual da atividade humana de trabalho que fundamente a compreensão das relações saúde-trabalho, necessária à eficiência das práticas.

\title{
2.1. A saúde como gestão de si em um meio singular
}

A doença no trabalho é fenômeno oriundo de modos de trabalhar concretos em contextos específicos de produção. Porém, essa relação entre o humano em atividade de trabalho e o meio produtivo não pode ser compreendida enquanto uma relação determinística. No que se refere à ontogenia humana, o meio não age diretamente sobre a ordem biológica. Saúde e Doença são realidades construídas a partir de uma complexa interação entre as concretudes da condição humana e a elaboração de sentidos. Essa elaboração pressupõe um debate entre a normatividade vital e a normatividade social, o que significa que as relações entre cada homem e seu meio mobiliza em si mesmo um complexo sistema de valores que fundamenta sua atividade normativa. A vida não é indiferente às suas próprias condições, ao contrário, viver é posicionar-se (Canguilhem, 1966).

Tais afirmações originam-se em alguns pressupostos sobre a especificidade da interação entre o corpo humano e seu meio. Canguilhem nos incita a pensá-la como uma relação de tipo biológico, em contraposição à idéia de uma relação de tipo físico-químico. Uma relação de tipo biológico vai além de um conjunto de respostas reflexas que pressupõem um corpo contido em um meio em estado de submissão a um conjunto de mecanismos físico-químicos "Ora, a especificidade do ser vivo é compor o seu próprio meio" (Canguilhem, 1965, p. 143, tradução livre) -, o que afirma este meio como fruto de uma elaboração de sentido : "Um sentido, do ponto de vista biológico é uma apreciação 
de valores relacionada à uma necessidade. E uma necessidade é para quem a experimenta e a vive, um sistema de referência irredutível e portanto, absoluto" (idem, p. 154, tradução livre).

30 Uma relação de tipo biológico pressupõe a totalidade de um organismo em relação com o meio, o que exige compreender que "o organismo e o meio se relacionam do mesmo modo que as partes e o todo no interior do próprio organismo" (Canguilhem, 1965, p. 144, tradução livre). Esta unidade biológica em relação só pode existir se centrada no significado da vida do ser expresso em suas próprias normas internas. "Entre o ser vivo e o meio, a relação se estabelece como um debate, onde o ser vivo aporta suas próprias normas de apreciação das situações, onde ele busca dominar o meio e acomodá-lo" (idem, p. 146, tradução livre). E estas normas internas referenciam-se na vida em si mesma.

31 O meio humano é centrado no significado da vida do homem, o que faz com que este meio esteja em permanente reconstrução orientada pelos sentidos atribuídos ao meio pelo próprio homem. Não basta portanto que o meio carreie impulsos, é preciso que estes impulsos sejam percebidos, o que implica uma atitude vinculada à experiência do ser. "No homem, diferentente do animal de laboratório, os estímulos ou os agentes patogênicos não são jamais recebidos pelo organismos como fatos físicos brutos, mas são também vividos pela consciência como sinais de tarefas ou de provas"(Canguilhem, 1966, p. 204, tradução livre).

32 As contingências humanas só encontram sentido na experiência humana e diferentes respostas se constroem frente às influências do meio de acordo com as possibilidades da vida coletiva em uma determinada cultura. "O ser humano pode desenvolver diversas soluções para um mesmo problema posto pelo meio" (Canguilhem, 1965, p. 142, tradução livre). Ao transformar o meio pela inventividade técnica, os homens aplicam aí o mesmo princípio, a transformação do meio em função de si mesmos e dos valores que constituem sistemas de referência frente às necessidades da vida ao longo da história. Do mesmo modo, as relações sociais entre os homens se estabelecem como ligações em torno deste mesmo sistema de referências. Ao mesmo tempo em que ocorrem transformações no modo de viver, o humano se constitui e as características do modo de viver se tornam parte da ontogenia humana, o que significa que a dinâmica de constituição do indivíduo e a dinâmica de constituição do meio são interconstituintes ou mutuamente gerativas. (Maturana, 2001)

33 O corpo humano aqui se inscreve, estruturando-se nesta permanente relação com este meio técnico-social mas, esta não é uma relação determinística. “A forma e as funções do corpo humano não são expressão de condições impostas à vida pelo meio, mas expressào de modos de viver em meios socialmente adotados" (Canguilhem, 1966, p. 203, tradução livre)

0 meio não infiltra-se por entre as membranas do corpo independentemente das suas próprias normas internas e a permeabilidade destas membranas é dada não apenas por um conjunto de mecanismos físico-químicos, mas também por um complexo sistema de valores que fundamenta sua atividade normativa.

Conceituar a vida como atividade normativa, idéia central da tese de Canguilhem, deriva importantes implicações sobre a noção de saúde, que aqui se refere à experiência humana, enquanto tentativa de singularizar o meio em função de suas próprias normas internas e como tal, de suas próprias normas de saúde e dos valores que as sustentam. 
36 A produção de conhecimentos sobre a saúde e a doença não deve portanto dissociar-se desse eixo fundamental que as situam como experiência humana, originada nos debates entre a história de cada um e o meio onde sua vida se faz possível. E aqui, a pretendida universalidade dos conceitos não substitui jamais a singularidade da experiência que cada um faz desta polaridade entre as normas vitais e as normas sociais, onde a saúde se manifesta como possível construção de si-mesmo em um meio reconhecido como próprio, sendo portanto, critério implícito do viver.

\subsection{A Atividade humana de trabalho}

37 O ponto de vista da atividade humana constitui o cerne da abordagem ergológica (Schwartz, 2000, 2007). As análises do trabalho que aí se baseiam evocam necessariamente as relações entre os valores, os saberes e o agir em competência, configuradas na especificidade das situações concretas de trabalho, o que exige fazer emergir a experiência de quem trabalha. Este posicionamento gera conseqüências para a produção dos saberes sobre o trabalho humano e especialmente no campo das relações saúde-trabalho.

Do ponto de vista ergológico, a experiência humana no trabalho constitui-se através de uma permanente gestão de si mesmo, condição para o agir em competêncianas situações produtivas. $O$ que pressupõe que o ato de trabalhar não se restringe a um uso hetero-determinado de homens e mulheres pelos gestores dos sistemas de produção, mas é também uma experiência de si mesmo, uma relação com a própria história. "A gestão, como verdadeiro problema humano, advém por toda parte onde há variabilidade, história, onde é necessário dar conta de algo sem poder recorrer a procedimentos estereotipados. Toda gestão supõe escolhas, arbitragens, uma hierarquização de atos e objetivos, portanto, de valores em nome dos quais estas decisões se elaboram". (Schwartz, 2004, p. 23)

39 A normatividade social objetivada nas situações de trabalho não exclui a variabilidade dos eventos técnicos, sociais e humanos inerentes aos processos produtivos, que resta a ser gerida pelo trabalho humano. As lacunas normativas são bem demonstradas pela Ergonomia da atividade ao revelar a diferença entre o trabalho prescrito e o trabalho real. A Ergologia re-afirma esta diferença, ao aprofundar seu significado. A atividade humana de trabalho exige uma permanente arbitragem entre o uso de si por si mesmo e o uso de si por outros, o que significa um permanente debate entre o que a Ergologia nomeia "normas antecedentes" e as normas inscritas na história do corpo de quem trabalha, suas próprias normas internas.

40 Arbitrar entre "o uso de si por si mesmo e o uso de si por outros" implica em renormalizações, em que as normas antecedentes serão re-interpretadas com o objetivo de reajustálas a si mesmo e à situação presente. As renormalizações envolvem escolhas e portanto, critérios. Tais critérios relacionam-se ao universo de valores que habita em nós, ao qual se referem os debates de normas. Podemos aqui evidenciar uma afirmação ergológica fundamental: a atividade humana é um re-trabalho permanente de um universo de valores, re-trabalho aqui entendido como re-definição e re-hierarquização.

41 Trabalhar é gerir-se em um meio circunscrito por normas de ordens técnica, organizacional, gerencial, por entre as estruturas produtivas que hetero-determinam os objetivos do trabalho humano, seus instrumentos, seu tempo, seu espaço. Porém, tais níveis de hetero-derminação não excluem a atividade humana em sua mobilização de 
saberes e valores incorporados nas práticas, condição para a o agir competente em um meio produtivo em constante transformação.

\subsection{A gestão da saúde no trabalho}

42 Se tomamos a atividade humana de trabalho como uma permanente gestão de si, referenciada no agir em competência em um meio produtivo, somos confrontados a uma única possibilidade de encontrá-la, qual seja, através da descoberta de suas formas singulares.

Esta afirmação traz consequências importantes sobre os conhecimentos necessários à gestão da saúde e dos riscos no trabalho, uma vez que implica acessar a singularidade das experiências individuais e coletivas de reconhecimento e hierarquização dos riscos diante da especificidade das situações de trabalho. A diversidade das situações produtivas e das histórias de cada corpo produtivo em seus saberes sedimentados, configura campos de possibilidades de gestão dos riscos também diferenciados, conforme a variabilidade das situações e das histórias pessoais e coletivas. De qualquer modo, a gestão de si e da própria saúde enquanto elemento estrutural da atividade humana de trabalho não se dissocia desta enquanto agir competente. E o agir competente é fundamentalmente determinado pelos valores que circulam através da atividade de trabalho. A hierarquização dos riscos é portanto, substanciada pela hierarquização dos valores que sustentam as normas internas de saúde e a relação com o próprio corpo em atividade. É esta dinâmica valorativa que possibilita a singularização do meio produtivo enquanto tentativa de construção de um meio coerente com as próprias normas de vida.

Ocorre que os valores mercantis, quantificáveis que sustentam as normas produtivas, entre elas as normas de gestão da saúde e da segurança no trabalho-, e os valores do viver comum, não-dimensionáveis que sustentam o agir em competência construído individual e coletivamente na especificidade das situações produtivas -, tendem ao conflito. Tais conflitos de valores possuem freqüentemente força suficiente para inviabilizar a efetivação das normas prescritas pelos gestores da saúde e segurança.

Quanto mais os princípios da gestão prescrita dos riscos afastam-se da singularidade das situações de trabalho e das renormalizações aí operadas, menores se tornam as chances de uma eficiência preventiva. Paradoxalmente é este mesmo afastamento que origina a gestão dos riscos enquanto instância especializada. Do mesmo modo que a tayloriana administração científica do trabalho requer, para se efetivar, a dissociação entre o trabalho e a gestão do trabalho, a administração científica da saúde e da doença no trabalho, requer a dissociação entre o trabalho e a gestão dos riscos no trabalho. Esta dissociação é uma condição para a própria existência da gestão especializada.

Tais afirmações são corroboradas pelos trabalhos de Damien Cru (Cru \& Dejours, 1983) no setor de construção civil, onde os "saberes-fazer de prudência", enquanto saberes integrantes do métier, se revelam em comportamentos solidamente baseados no conhecimento dos riscos das situações concretas de trabalho. Esses comportamentos tendem a se opor às medidas de prevenção preconizadas pelos especialistas, o que é interpretado por estes como um modo de resistência movido pela ignorância ou pela inconsciência dos trabalhadores. Em contraposição a esta interpretação, Cru demonstra que : 
"...a coletividade trabalhadora prefere renunciar à prevenção vinda do exterior, para continuar a se apoiar sobre a prevenção espontânea, originada do saber-fazer, do métier e das tradições dos trabalhadores da construção. Assim, mobilizam-se os saberes-fazer de prudência, que se exercem nos sistemas de auto-regulação do coletivo de trabalho, e de auto-regulação dos ritmos e dos modos operatórios individuais. Trata-se de um afrontamento entre uma organização espontânea do trabalho e uma organização imposta pelos engenheiros, afrontamento este onde se exerce um conflito fundamental entre duas concepções de segurança"(Cru \& Dejours, 1983, p. 239-240, tradução livre).

47 Nouroudine (2004) ao problematizar a noção de risco, defende a hipótese da necessária infração das normas de segurança prescritas como condição para a produção dos saberesfazer de prudência, tomando-os como essenciais tanto para a eficácia dos sistemas produtivos, como para a gestão da saúde no trabalho. As relações entre o risco e a atividade humana são abordadas aqui enquanto experiência e tal abordagem questiona a objetivação do risco de modo externo ao curso da atividade de trabalho em tempo real. Reconhecendo o risco como inerente à atividade de trabalho, "a análise do risco acarreta a busca pelos meios (organizacionais, técnicos e humanos) de forma a favorecer sua gestão, o que leva a considerá-lo positivamente" (idem, p. 44, tradução livre).

A gestão dos riscos no trabalho, concebida enquanto uma prática de especialistas, e enquanto tal, distanciada das reais possibilidades de gestão da saúde na atividade de trabalho, traduz-se em uma normatividade dissociada das reais situações de risco. Trinquet bem sintetiza esta questão ao constatar que “... a regulamentação está sendo insuficientemente aplicada, mas isto ocorre, sobretudo, porque ela é dificilmente aplicável em seu estado, considerando-se as condições globais atuais de realização da produção (econômicas, técnicas, sociais, culturais, organizacionais, etc.)"(Trinquet, 1996, p. 305, tradução livre).

As reais situações de risco se configuram em meio a uma complexa elaboração de compromissos por entre os intertícios da produção, entre padrões normativos e variabilidade, entre os limites do corpo e as exigências da produção, entre a própria história e a história dos outros que compartilham a produção. Permanente arbitragem, onde a gestão da própria saúde convoca muitas vezes valores desconhecidos do mundo dos especialistas, o que aumenta a distância entre estes dois mundos, o mundo da gestão especializada da saúde no trabalho e o mundo da gestão real da saúde no trabalho.

"Restituir a densidade do espaço onde se operam estes compromissos e arbritagens parece-nos necessário para recusar a tese de que não há gestão senão a dos especialistas habilitados como tais" (Schwartz, 2004, p. 26). Esta é uma condição para a construção de princípios de prevenção que atinjam a gênese patogênica das situações de trabalho, configurada na singularidade das renormalizações possíveis da atividade de trabalho em contextos específicos. 


\section{A gestão da saúde no trabalho como questão coletiva}

51 A atividade humana de trabalho e o fenômeno saúde-doença no trabalho são duas faces de uma mesma moeda e se processam em um mesmo eixo histórico, por entre mediações da estrutura psicobiológica humana em circunstâncias produtivas ao mesmo tempo singulares e coletivas. Se afirmamos que a saúde e a doença se constituem essencialmente no plano da experiência sempre singular de cada ser humano em seu modo de viver, como conceituar estas configurações sociais que expressam a doença como experiência coletiva? Como se configuram estas situações enquanto terreno comum da experiência humana? Como se constroem os processos interativos entre os indivíduos imersos na singularidade das situações? Como se processam as relações entre a comunidade do viver e o trabalhar e a comunidade do adoecer?

Tais questões nos remetem à Epidemiologia, enquanto disciplina que pretende contribuir para a interpretação e análise da dimensão coletiva no campo da saúde e da doença. Almeida Filho (1992) explicita o objeto de estudo da Epidemiologia como as ocorrências de saúde-doença em massa, envolvendo um número expressivo de pessoas, agregados em sociedades, coletividades, comunidades, grupos demográficos, classes sociais, ou outros coletivos de seres humanos. Gonçalvez (1990) o define como a dinâmica gênese e devir dos processos saúde-doença em populações concretas, com todas as características históricas e sociais que as especificam.

53 A definição ou as definições de coletivo que perpassam os estudos epidemiológicos nos remete ao núcleo dessa disciplina. Para Breilh (1994), o enfoque da relação coletivoindivíduo tem consequências que dizem respeito aos próprios fundamentos da disciplina epidemiológica, repercutindo sobre sua metodologia, suas técnicas e sobretudo, sobre sua projeção prática como ferramenta de transformação das condições da vida humana. Barreto e Alves (1994) tecem longas críticas à forma como a noção de coletivo é usualmente referida na literatura epidemiológia, uma entidade definida em termos de um sistema objetivo de relações sociais, à parte das manifestações individuais e esvaziado de força explicativa. Visto a partir de uma perspectiva estruturalista, o coletivo torna-se uma realidade em si, o que pressupõe a idéia da determinação social sobre os fenômenos coletivos emergentes. Esta definição contrapõe-se aos estudos que enfocam as interações sociais e demonstram que os indivíduos constantemente monitoram suas ações, ao negociar, adaptar e modificar significados e contextos, revelando as formações coletivas como construção de significados resultantes de processos interativos.

54 As implicações das circuntâncias estruturais não podem ser negligenciadas, especialmente quando tratamos da saúdedoença enquanto fenômeno coletivo. Porém, a atividade humana, enquanto fundamento do viver, exige o movimento de singularização, fazendo com que as circunstâncias sejam sempre transformadas pela experiência humana de acordo com as possibilidades da vida coletiva em uma determinada cultura e dos valores que constituem sistemas de referência frente às necessidades da vida ao longo de sua história. Do mesmo modo, as relações sociais entre os homens se estabelecem como ligações em torno deste mesmo sistema de referências.

55 Ao afirmar a especificidade do trabalho como gênese de processos coletivos de adoecimento, cabe indagar : como podemos acessar as configurações coletivas que nos 
permitiriam compreender a doença como processo moldado no agir em situação de trabalho?

Na busca de elementos de resposta para esta questão, a noção de Entidades Coletivas Relativamente Pertinentes (ECRP) [5] nos instrumentaliza no sentido de alcançar as relações entre o polo dos macro-territórios da gestão global das atividades econômicas e da política, e o polo dos micro-territórios onde se processam as atividades humanas. As ECRP representam a dinâmica do viver comum, carreando o re-trabalho dos valores entre o macro e o micro. Espécies de matrizes da história, são existentes em toda organização humana.

57 A denominação Entidades Coletivas refere-se à invisibilidade de suas fronteiras, na medida em que estas se revelam em coletivos mutantes, com contornos variáveis, independentes das configurações sociais pré-determinadas. São caracterizadas como relativamente pertinentes porque se referem a laços que se tecem no viver comum, a partir do compartilhamento de objetivos e valores, em uma permanente construção e reconstrução, condição da imprevisibilidade de sua dinâmica e de suas fronteiras, que são aquelas da atividade humana em um determinado momento. A configuração das ECRP ocorre em função, de um lado, dos valores socialmente compartilhados, valores estes não dimensionáveis, que fundamentam o viver comum; de outro, em função das necessidades de eficácia coletiva ou da construção das competências do viver.

As ECRP compõem os ingredientes das competências mobilizados na atividade humana em situação de trabalho, envolvendo a capacidade de construção de sinergias entre diferentes histórias e perfis de competência em torno dos objetivos do trabalho (o que não corresponde necessariamente às equipes profissionais pré-definidas pelos gestores do trabalho). Trata-se de uma condição do agir competente, no sentido da superação das lacunas oriundas da divisão formal do trabalho, diante da variabilidade das situações produtivas, e também no sentido de possibilitar a apropriação coletiva da dimensão singular e histórica das situações de trabalho, funcionando aqui como polo de gestão coletiva, palco de debate de normas e de re-trabalho dos valores.

59 A dinâmica valorativa que sustenta as ECRP, relacionada à hierarquização dos valores que circulam no contexto técnico e social de uma dada situação de trabalho, delimita os campos de possibilidades da gestão individual e coletiva das situações de risco. Isto significa que a gestão de si e da própria saúde em situação de trabalho possui uma dupla inscrição, as normas internas de saúde, relacionadas à história individual, e as normas do agir competente, relacionadas à história das situações produtivas, centradas no compartilhamento dos valores objetivados em competência coletiva.

\section{Considerações finais}

Compreender a produção da doença no trabalho enquanto processo moldado no agir individual e coletivo em situação de trabalho exige acessar as histórias das situações de trabalho, em suas interações sempre singulares entre a atividade humana e os meios técnicos e sociais que configuram o viver e o trabalhar em contextos específicos.

61 Se assumirmos o ponto de vista da atividade humana a partir de uma abordagem ergológica, no sentido de pensar os modos de viver, trabalhar e adoecer das populações trabalhadoras, nos deparamos com uma única possibilidade de acesso às suas modalidades concretas, qual seja, encontrando-nos com as configurações singulares do 
viver e trabalhar, individuais e coletivas. Impõe-se, portanto, reconhecer que os conhecimentos científicos sobre as relações entre a saúde e o trabalho não alcançam o poder de determiná-las. A normatividade aí originada, que baseia a gestão especializada dos riscos do trabalho, será sempre debatida pela experiência humana, e se pretendemos alcançar alguma eficiência preventiva, será preciso trazer à tona as experiências individuais e coletivas das confrontações normativas.

É neste sentido que a Ergologia propõe um regime de produção de saberes sobre o trabalho na forma de um Dispositivo Dinâmico a Três Polos (Schwartz, 2000). Trata-se de engendrar a cooperação entre pesquisadores e trabalhadores, onde a competência humana no trabalho possa interrogar e ser interrogada pelos saberes das diversas disciplinas científicas, de forma a assegurar um equilíbrio entre as exigências epistemológicas e protocolares e os saberes derivados das histórias individuais, através de um permanente diálogo entre os saberes acadêmicos e os saberes imanentes às atividades e re-trabalhados por estas.

\section{BIBLIOGRAFIA}

Almeida Filho A.(1992). Introdução à Epidemiologia Moderna, 2a edição. Belo Horizonte : COOPMED/ABRASCO.

Barreto M.L. \& AlvesP. (1994). O coletivo versus o individual na Epidemiologia : Contradição ou Síntese , In II Congresso Brasileiro de Epidemiologia. Belo Horizonte : COOPMED/ABRASCO, 184-191.

Breilh J.(1994). Dialéctica de lo coletivo en Epidemiologia, In Anais do II Congresso Brasileiro de Epidemiologia. BH : COOPMED/ABRASCO, 98-105.

Canguilhem G. (1965). La connaissance de la vie. Paris : PUF Canguilhem G. (1966). Le normal et le pathologique. Paris : PUF

Coutarel F.,Daniellou F. e Dugué B.(2005). La prévention des troubles musculo-squelettiques : quelques enjeux épistémologiques. @ctivités, 2 (1), 3-18, http://www.activites.org

Cru,D. \& Dejours,C.(1983) Les savoir-faire de prudence dans les metiers du batiment. Les cahiers medico-sociaux 27éme anée (3), 239-247.

Duraffourg J. (2008). Santé au travail, Santé du travail, Ergologia, 0, 155-176.

Echternacht E. (1998). As Lesões por Esforços Repetitivos no contexto da reestruturação produtiva brasileira, Tese de Doutorado, COPPE/ UFRJ, Rio de Janeiro.

Gonçalvez R.B.M. (1990) Contribuição à Discussão sobre as Relações entre teoria, objeto e método em Epidemiologia. In Anais do I Congresso Brasileiro de Epidemiologia. Campinas/SP : ABRASCO, 76-88.

Maturana H.(2001) Biologiadopsíquico, Ondeestáamente ? In Magro,C. ; Graciano,M. e Vaz,N. (Orgs), A Ontologia da Realidade (pp107-122). Belo Horizonte : Ed. UFMG. 
Minayo,M.C.S. (1993) O desafio do conhecimento : Pesquisa Qualitativa em Saúde. Rio de Janeiro : HUCITEC/ABRASCO.

Minayo,M.C.S. (1994) Quantitativo e Qualitativo em Indicadores de Saúde : Revendo conceitos In II Congresso Brasileiro de Epidemiologia. Belo horizonte : COOPMED/ABRASCO, 83-92.

Nouroudine, A. (2004). Risco e atividades humanas : acerca da possível positividade aí presente. In Figueiredo,M. ; Athayde, M. ; Brito, J. ; Alvarez,D. (Orgs.), Labirintos do trabalho : interrogações e olhares sobre o trabalho vivo (pp. 37-62). Rio de Janeiro : DP\&A Editora

Oddone, I. (1981). Redécouvrir l'expérience ouvrière. Messidor : Éditions Sociales

Rantanen J. (1995). Novas Epidemias em Saúde Ocupacional. Quais são e como identificá-las. La Medicina del Lavoro. 86/2, 139-151.

Schwartz Y. (2000). Le paradigme ergologique ou un métier de Philosophie. Toulouse : Octarès.

Schwartz, Y.(2004). Trabalho e gestão : níveis, critérios,instâncias. In Figueiredo,M. ; Athayde, M. ; Brito, J. ; Alvarez,D. (Orgs.), Labirintos do trabalho : interrogações e olhares sobre o trabalho vivo (pp. 2333). Rio de Janeiro : DP\&A Editora

Schwartz Y. (2007). Un bref aperçu de l'histoire culturelle du concept d'activité. @ctivités,4(2), 122-133, http://www.activites.org

Thébaud-Mony,A.(2006). Histoires profissionelles et cancer. Actes de la recherche en Sciences Sociales, n.163, pp18-31.

Trinquet, P. (1996). Maîtriser les risques du travail. Paris : PUF

Vidal, M.C.R. (1993). Programa Científico do Grupo de Ergonomia e Novas Tecnologias COPPE/ UFRJ, Rio de Janeiro : COPPE/UFRJ

Wisner, A. (1995). Réflexions sur L'ergonomie, 1962-1995. Toulouse : Octarès.

\section{RESUMOS}

Este estudo objetiva refletir sobre as perspectivas de ampliação dos campos de possibilidades preventivas sobre os impactos dos atuais modos de viver e trabalhar na saúde das populações trabalhadoras. $\mathrm{O}$ caminho percorrido referencia-se na abordagem ergológica, em seus esforços de compreensão do trabalho humano a partir do conceito de atividade. Situando-nos no contemporâneo contexto sócio-técnico global, partimos da constatação empírica da ineficiência das atuais práticas preventivas e nos guiamos através da hipótese da insuficiência dos modelos hegemônicos de investigação das relações saúde-trabalho diante da complexidade do problema. Procuramos neste percurso pensar as relações entre a gestão da saúde no trabalho e a construção dos saberes sobre o trabalho. Nossas conclusões apontam para a necessária incorporação dos sujeitos do trabalho na construção dos saberes necessários à compreensão da singularidade das situações de trabalho nas diversas configurações sócio-técnicas como condição para o alcance de uma eficiência preventiva.

Este estudio objetiva reflexionar sobre las perspectivas de ampliación de los campos de posibilidades preventivas sobre los impactos de los actuales modos de vivir y trabajar en la salud de las poblaciones trabajadoras. El camino recorrido se referencia en el planteamiento ergológico, en sus esfuerzos de comprensión del trabajo humano a partir del concepto de actividad. Situándonos en el contemporáneo contexto socio-técnico global, partimos de la constatación empírica de la ineficiencia de las actuales prácticas preventivas y nos guiamos a 
través de la hipótesis de la insuficiencia de los modelos hegemónicos de investigación de las relaciones salud-trabajo delante de la complejidad del problema. Procuramos en este recorrido pensar las relaciones entre la gestión de la salud en el trabajo y la construcción del saber sobre el trabajo. Nuestras conclusiones apuntan para la necesaria incorporación de los sujetos del trabajo en la construcción del saber necesario a la comprensión de la singularidad de las situaciones de trabajo en las diversas configuraciones socio-técnicas como condición para el alcance de una eficiencia preventiva.

Cette étude traite du déploiement des champs de possibilités préventives concernant les effets des modes actuels de vie et de travail sur la santé des travailleurs. Le chemin parcouru a pour référence l'approche ergologique, dans sa volonté de compréhension du travail humain à partir du concept d'activité. En nous situant dans le contexte socio-technique global contemporain, nous partons de la constatation empirique de l'inefficience des pratiques préventives actuelles et sommes guidés par l'hypothèse de l'insuffisance, face à la complexité du problème, des modèles hégémoniques de la recherche relative aux relations santé-travail. Dans ce parcours, nous cherchons à mieux situer les relations entre la gestion de la santé au travail et la construction des savoirs sur le travail. Nos conclusions vont dans le sens d'une incorporation des sujets du travail dans la construction des savoirs nécessaires à la compréhension de la singularité des situations de travail, dans les configurations socio-techniques diverses, comme condition pour la réussite d'une prévention efficiente.

This paper's goal is a reflection about the perspectives of enlargement of the preventive possibilities, concerning the impacts of present ways of living and working in the health of working populations. This reflection is based on the ergologic approach, on its efforts to understand human work based on the concept of activity. Placing ourselves in the present global socio-technical context, we start from the empirical contatation of the inefficiency of present preventive practices and guide ourselves through the hipotesis that the hegemonic reseach models of the relations between work and health are insuficient, considered the complexity of the problem. Throughout this journey, we try to think the relations between health management at work and knowledge construction about work. Our conclusions point out to the necessary incorporation of the subjects of work in the construction of the knowledge needed for the compreention of the singularity of work situations in diverse socio-technical configurations as a condition for attaining preventing efficiency.

\section{ÍNDICE}

Mots-clés: production, activité humaine de travail, gestion de la santé au travail, confrontation de savoirs, approche ergologique

Palabras claves: producción, actividad humana de trabajo, gestión de la salud en el trabajo, confrontación del saber, planteamiento ergológico

Keywords: production, human work activity, health management at work, knowledge confrontation, ergologic approach

Palavras-chave: produção, atividade humana de trabalho, gestão da saúde no trabalho, confrontação de saberes, abordagem ergológica 


\section{AUTOR}

\section{ELIZA ECHTERNACHT}

Universidade Federal de Minas Gerais, Av. Antônio Carlos 6627 Campus Pampulha, Escola de Engenharia Departamento de Engenharia de Produção, sala 3103 Laboratório Produção e Saúde, Belo Horizonte, Minas Gerais

eliza@dep.ufmg.br 